\title{
MATURATION ALTERS THE PULMONARY ARTERIAL RESPONSE TO HYPOXIA AND INHALED NITRIC OXIDE IN THE PRESENCE OF ENDOTHELIAL DYSFUNCTION
}

\author{
Jeff L. Myers, MD, $\mathrm{PhD}^{\mathrm{a}}$ \\ Joseph J. Wizorek, BS ${ }^{\mathrm{a}}$ \\ Adam K. Myers, PhD $^{b}$ \\ Michael O'Donoghue ${ }^{a}$ \\ Maria T. Pettit, BS ${ }^{a}$ \\ Peter C. Kouretas, MD ${ }^{a}$ \\ Heidi J. Dalton, $\mathrm{MD}^{\mathrm{c}}$ \\ Yining Wang, $\mathrm{MD}^{\mathrm{a}}$ \\ Richard A. Hopkins, MD ${ }^{a}$
}

\begin{abstract}
Surgical intervention in ever younger patients has led to a new appreciation of the unique physiology of the neonate. Specifically, newborn patients may respond very differently to hypoxic episodes and subsequent treatment with inhaled nitric oxide than older infants. In the current study, we examined differences in the pulmonary arterial response to hypoxia and inhaled nitric oxide in 48-hour-old $(n=8)$ and 14-day-old $(n=8)$ Yorkshire pigs in a model of nitric oxide synthase inhibition, as might be seen with endothelial dysfunction. Data were acquired after treatment with the nitric oxide synthase inhibitor $N \omega$-nitro-L-arginine during hypoxia (inspired oxygen fraction $=0.10)$ and during inhalation of nitric oxide $(100 \mathrm{ppm})$. Input mean impedance, reflecting distal arteriolar vasoconstriction, and characteristic impedance, reflecting proximal arterial geometry and distensibility, were calculated. The modulus of elasticity, a measure of the "stiffiness" of the proximal vessels, was also calculated. Hypoxia caused a large increase in input mean impedance in both 48-hour-old and 14-day-old pigs (4826 \pm 272 versus $8744 \pm 488 \mathrm{dyne} \cdot \mathrm{cm} \cdot \mathrm{sec}^{-5}$ and $3129 \pm 73$ versus $6000 \pm 134$ dyne $\cdot \mathrm{cm} \cdot \sec ^{-5}$, respectively; $p=0.0078$ ). Characteristic impedance was not altered in the younger animals $\left(1171 \pm 76 \mathrm{dyne} \cdot \mathrm{cm} \cdot \mathrm{sec}^{-5}\right)$ but increased in the older animals $\left(419 \pm 15\right.$ versus $797 \pm 20 \mathrm{dyne} \cdot \mathrm{cm} \cdot \mathrm{sec}^{-5}$, $p=0.0078$ ). Older animals also experienced an increase in the modulus elasticity $\left(1.92 \mathrm{E}^{06} \pm 3.2 \mathrm{E}^{05}\right.$ versus $\left.1.05 \mathrm{E}^{07} \pm 3.9 \mathrm{E}^{05} \mathrm{dyne} / \mathrm{cm}^{2}, p=0.0078\right)$. These data show that inhibited nitric oxide production, as might be seen in endothelial dysfunction, potentiates the profound hypoxic vasoconstriction observed at the level of the distal pulmonary arterioles in both neonatal and infant animals. In contrast, only older animals had a stiffening of the larger, more proximal vessels with hypoxia. In both age groups, inhaled nitric oxide effectively reduced the increases in impedance. ( $J$ Thorac Cardiovasc Surg 1997;113:270-7)
\end{abstract}

D iscovery of the endothelium-derived relaxing factor (EDRF) by Furchgott and Zawadzki ${ }^{1}$ was the first indication of the importance of the vascular

From the Departments of Surgery, ${ }^{a}$ Physiology and Biophysics, ${ }^{b}$ and Pediatrics, ${ }^{c}$ Georgetown University Medical Center, Washington, D.C.

Read at the Seventy-sixth Annual Meeting of The American Association for Thoracic Surgery, San Diego, Calif., April 28-May 1, 1996.

Received for publication May 6, 1996; revisions requested June 21, 1996; revisions received Sept. 30, 1996; accepted for publication Oct. 18, 1996.

Address for reprints: Richard A. Hopkins, MD, Professor and Chief, Cardiothoracic Surgery, 164 Summit Ave., Providence, RI 02906.

Copyright (C) 1997 by Mosby-Year Book, Inc.

$0022-5223 / 97 \$ 5.00+0 \quad \mathbf{1 2 / 6 / 7 8 7 7 3}$ endothelium in determining both resting hemodynamics and the response to stressors such as hypoxia. However, it is unclear how these responses are affected by the rapid changes occurring in the very early postpartum period. In the first hours and days after birth, pulmonary artery pressure, pulmonary vascular resistance, and impedance fall dramatically, whereas flow rises. ${ }^{2}$ Use of the nitric oxide synthase inhibitor $N \omega$-nitro-L-arginine (L-NA) in fetal sheep has been shown to prevent the normal postnatal changes of the pulmonary circuit, indicating the requirement for an intact and functional endothelium for normal maturation. ${ }^{3}$ One aim of the current experimental series is to determine age-specific differences in the response to hypoxia and inhaled nitric oxide in a model of dysfunctional endothelium. Because both surgical manipulation and car- 
diopulmonary bypass damage the endothelium and inhibit its ability to respond to potential stressors, ${ }^{4,5}$ these studies are of importance in understanding the unique pulmonary arterial circulation of the newborn infant.

Use of hydraulic impedance analysis allows a complete description of the energy contained within the pulmonary arterial pressure and flow waveforms. Energy contained within the pulsatile components of the waveforms can be analyzed and total right ventricular energy expenditure can be defined. Characteristic impedance is determined by the compliance and geometry of the proximal vessels. By measurement of radius and elasticity, it can be determined whether changes in characteristic impedance represent active alterations in the properties of the vessel wall. Input mean impedance is determined by mean terms and represents distal arteriolar vasoconstriction. It is highly analogous to pulmonary vascular resistance.

\section{Materials and methods}

All animals received humane care in compliance with the Georgetown Animal Care and Use Committee (GUACUC) and "Principles of Laboratory Care" formulated by the National Society for Medical Research and the "Guide for the Care and Use of Laboratory Animals" prepared by the National Institutes of Health (NIH publication No. 85-23, revised 1985).

Surgical preparation. Eight 48-hour-old and eight 14 day-old Yorkshire piglets of either sex were used in this study. The ear vein was catheterized and the animals were anesthetized with intravenous thiopental sodium $(25 \mathrm{mg} /$ $\mathrm{kg}$ ). A half dose of this agent was administered every 20 minutes.

After endotracheal intubation the animals were placed in the supine position and their lungs were ventilated with a pediatric positive-pressure ventilator (Health dyne 105, Marietta, Ga.). Surgical preparation and the collection of baseline data were performed at an inspired oxygen fraction of 1.0; this maintained an arterial oxygen saturation of $95 \%$ or greater. Positive inspiratory pressure was preset between 15 and $25 \mathrm{~cm} \mathrm{H}_{2} \mathrm{O}$ and respiratory rate between 9 and 10 ventilations per minute. These settings achieved an arterial partial pressure of carbon dioxide $\left(\mathrm{PaCO}_{2}\right)$ of 35 to $45 \mathrm{~mm} \mathrm{Hg}$. To prevent atelectasis, a positive end-expiratory pressure of $3 \mathrm{~cm} \mathrm{H} \mathrm{H}_{2} \mathrm{O}$ was used.

Pancuronium bromide $(0.1 \mathrm{mg} / \mathrm{kg}$ intravenously) was given to produce complete muscle relaxation. A titanium clip (Ethicon, Inc., Somerville, N.J.) was used to occlude the ductus arteriosus and separate the pulmonary and systemic circulations. Sonomicrometry crystals for continuous measurement of diameter changes were placed on the lateral aspects of the main pulmonary artery with 4-0 silk sutures. An ultrasonic flow probe (Transonic Systems, Ithaca, N.Y.) was placed around the most proximal portion of the main pulmonary artery. A 6 or $8 \mathrm{~mm}$ ultrasonic flow probe (type 65 or 85 ), chosen for best fit while avoiding constriction of the vessel, was used. High-fidelity pressure transducers (model SPR-524, Millar Instruments, Inc., Houston, Tex.) were placed into the left atrial appendage and the main pulmonary artery. Each transducer was secured by a 4-0 silk purse-string suture. Premeasurement of the pulmonary artery transducer length in relation to the main pulmonary artery ensured that the tip was positioned $2 \mathrm{~mm}$ beyond the flow probe to avoid any perturbation of waveforms. A third transducer was inserted into the right internal carotid artery for measurement of systemic pressures.

Experimental protocol. All animals underwent a 10minute equilibration period after instrumentation and were then given a $20 \mathrm{mg} / \mathrm{kg}$ dose of L-NA (Sigma Chemical Co., St. Louis, Mo.) via the intimal jugular catheter. Baseline data were collected at 3,5 , and 10 minutes after administration of L-NA. Nitrogen was then blended into the ventilator circuit until an inspired oxygen fraction of 0.10 was obtained, and data were again collected at 3,5 , and 10 minutes. While the animals were still hypoxic, nitric oxide infusion was begun through the inspiratory limb of the ventilator at a concentration of $100 \mathrm{ppm}$ (Roberts Oxygen, Rockville, Md.). The dose was chosen on the basis of our own dose-response curves (unpublished data) and the experience of others. ${ }^{6}$ Data collection was repeated at 3-, 5-, and 10-minute intervals. So that the effects of respiratory motion on pulmonary artery pressure and flow could be avoided, ventilation was briefly interrupted during data collection intervals without any observable changes in pulmonary or systemic parameters. ${ }^{7}$ Arterial blood oxygen $\left(\mathrm{PaO}_{2}\right), \mathrm{PaCO}_{2}$, and $\mathrm{pH}$ were determined with a CIBA Corning analyzer (model 278, Medfield, Mass.) at each "10-minute" interval. Alveolar gas concentration $\left(\mathrm{PaO}_{2}\right.$ and $\left.\mathrm{PaCO}_{2}\right)$ and arterial oxygen saturation were constantly monitored (POET II, Criticare Systems, Waukesha, Wis.). Nitric oxide levels were measured in the ventilator tubing as it entered the endotracheal tube with an electrochemical monitor (Pac II NO monitor, Drager, Inc., Chantilly, Va.). Data analysis and instrument calibration have been previously described. ${ }^{8}$

The dose of L-NA used was determined in a separate series of 48-hour-old $(n=8)$ and 14-day-old $(n=8)$ animals. The response to acetylcholine, an endotheliumdependent vasodilator $(10 \mu \mathrm{g}$ in $1 \mathrm{ml}$ normal saline solution, given intravenously) and sodium nitroprusside, an endothelium-independent vasodilator $(5 \mu \mathrm{g}$ in $1 \mathrm{ml}$ normal saline solution, given intravenously) was determined before and after L-NA administration. Response to both drugs was demonstrated by a rise in pulmonary artery flow and a fall in input mean impedance and pulmonary vascular resistance. Blockade of endothelial nitric oxide was considered complete at the dose sufficient to ablate the response to acetylcholine. Specificity of the blockade was demonstrated by preservation of the smooth muscle response to nitroprusside.

\section{Hemodynamic calculations}

Pulmonary vascular resistance, input mean impedance, and characteristic impedance. Pulmonary vascular resistance was calculated in the usual fashion:

$$
\overline{\mathrm{P}}_{\mathrm{PA}}-\overrightarrow{\mathrm{P}}_{\mathrm{LA}} / \overrightarrow{\mathrm{Q}}_{\mathrm{PA}}
$$


Table I. Response to hypoxia and inhaled nitric oxide

\begin{tabular}{|c|c|c|c|c|c|c|}
\hline & \multicolumn{3}{|c|}{ 48-hour-old piglets } & \multicolumn{3}{|c|}{ 14-day-old piglets } \\
\hline & Baseline & Hypoxia & Nitric oxide & Baseline & Hypoxia & Nitric oxide \\
\hline PAP & $17.4 \pm 1.5$ & $30.6 \pm 1.5^{*}$ & $16.1 \pm 1.1 \dagger$ & $12.6 \pm 0.7$ & $28.0 \pm 0.9 \dagger$ & $16.5 \pm 1.0^{\dagger}$ \\
\hline PAF & $5.8 \pm 0.9$ & $5.3 \pm 0.7$ & $5.2 \pm 0.9$ & $7.0 \pm 0.5$ & $6.6 \pm 0.5$ & $7.3 \pm 0.6^{*}$ \\
\hline LAP & $5.1 \pm 0.2$ & $5.3 \pm 0.2$ & $5.4 \pm 0.3$ & $3.6 \pm 0.1$ & $3.8 \pm 0.2$ & $3.5 \pm 0.2$ \\
\hline PVR & $3866 \pm 239$ & $7683 \pm 505 \dagger$ & $3541 \pm 226 \dagger$ & $1504 \pm 79$ & $4998 \pm 163 \dagger$ & $1626 \pm 106 \dagger$ \\
\hline AoP & $77.8 \pm 3.3$ & $73.9 \pm 7.1$ & $70.3 \pm 7.6 \dagger$ & $86.8 \pm 4.1$ & $88.7 \pm 6.0$ & $83.9 \pm 6.2$ \\
\hline $\mathrm{O}_{2}$ sat & $99.7 \pm 0.1$ & $30.8 \pm 2.8 \dagger$ & $33.5 \pm 2.6$ & $98.6 \pm 1.1$ & $25.0 \pm 1.4 \dot{\dagger}$ & $29.9 \pm 3.0$ \\
\hline $\mathrm{PaO}_{2}$ & $412.8 \pm 42.6$ & $18.3 \pm 1.2 \dagger$ & $20.2 \pm 1.4$ & $364.1 \pm 46.0$ & $17.2 \pm 0.5 \dagger$ & $25.9 \pm 3.2 \uparrow$ \\
\hline $\mathrm{R}_{\mathrm{mn}}$ & $3.82 \pm 0.21$ & $3.97 \pm 0.13$ & $3.91 \pm 0.14$ & $4.52 \pm 0.21$ & $4.94 \pm 0.20 \dagger$ & $4.89 \pm 0.20$ \\
\hline
\end{tabular}

Values presented as mean \pm standard error of the mean. $P A P$, Pulmonary artery pressure (mm Hg); $P A F$, pulmonary artery flow (ml/sec); $L A P$, left atrial pressure $(\mathrm{mm} \mathrm{Hg}) ; P V R$, pulmonary vascular resistance (dyne $\left.\cdot \mathrm{cm} \cdot \mathrm{sec}^{-5}\right) ; A o P$, aortic pressure $\left(\mathrm{mm} \mathrm{Hg}\right.$ ); $O_{2}$ sat, translingual arterial oxygen saturation; $\mathrm{PaO}_{2}$, arterial partial pressure of oxygen $(\mathrm{mm} \mathrm{Hg}) ; R_{m n}$, radius of main pulmonary artery at mean pulmonary arterial pressure $(\mathrm{mm})$.

${ }^{*} P<0.05$ versus preceding intervention.

$\uparrow P<0.01$ versus preceding intervention.

where $\mathrm{P}_{\mathrm{PA}}$ is the mean pulmonary artery pressure, $\mathrm{P}_{\mathrm{LA}}$ is the mean left atrial pressure, and $\mathrm{Q}_{\mathrm{PA}}$ is the mean pulmonary artery flow. Pulmonary arterial impedance calculations were based on a Fourier analysis of pressure and flow waves as previously described. ${ }^{8}$ Data collection periods were 30 seconds long, and 8 to 16 random heartbeats were analyzed for each data interval for each pig. Ten harmonics were calculated for each heartbeat. Total pulmonary flow is expressed as follows:

$$
\mathrm{Q}_{\mathrm{t}}=\mathrm{Q}_{\mathrm{m}}+\sum_{\mathrm{n}=1}^{10} \mathrm{Q}_{\mathrm{n}} \sin \left(\mathrm{n} \omega \mathrm{t}+\theta_{\mathrm{n}}\right)
$$

where $Q_{m}$ is the mean flow, $Q_{n}$ is the amplitude of the $n$th harmonic, $\omega$ is the fundamental angular frequency $(2 \pi f$ where $f$ is the frequency in $\mathrm{Hz}$ ), $t$ is the length of the sequence, and $\theta \mathrm{n}$ is the phase angle of the nth harmonic. Pressure waveforms are expressed as follows:

$$
P_{t}=P_{m}+\sum_{n=1}^{10} P_{n} \sin \left(n \omega t+\beta_{n}\right)
$$

where $P_{m}$ is the mean pressure, $P_{n}$ is the amplitude of the nth harmonic, and $\beta$ is the phase angle of the nth harmonic. Dividing mean pressure by mean flow produces the input impedance to flow at the 0th harmonic. Similarly, the division of each of the sinusoidal terms gives the input impedance for the nth harmonic. The corresponding phase angle $\left(\theta_{n}\right)$ was calculated from subtraction of the flow phase angle from the pressure phase angle. Characteristic impedance is defined as the impedance in the absence of wave reflections and was calculated between 3 and $10 \mathrm{~Hz}$.

Derivation of instantaneous elasticity measurements. Wave velocity $\left(\mathrm{C}_{\mathrm{o}}\right)$ was calculated for the main pulmonary artery assuming the relationship Womersley ${ }^{9}$ derived between characteristic impedance $\left(Z_{0}\right)$, wave velocity, and radius $(R)$ of a strongly tethered elastic tube:

$$
\mathrm{Z}_{\mathrm{o}}=\frac{\rho \mathrm{C}_{\mathrm{o}}}{\pi \mathrm{R}^{2} \sqrt{1-\sigma^{2}}} \cdot \frac{1}{\mathrm{M}_{10}} \cdot \mathrm{e}^{-\mathrm{j} \epsilon / 2}
$$

where $\rho=1055 \mathrm{gm} / \mathrm{ml}$, which is the density of blood; $\sigma=$ 0.5 , which is Poisson's ratio, and $\mathrm{j}=\sqrt{-1} . \mathrm{M}^{\prime}{ }_{10}$ and $\epsilon$ are functions of Womersley's nondimensional parameter $\alpha$ :

$$
\alpha=\mathrm{R} \sqrt{\omega \frac{\rho}{\mu}}
$$

where $\mu=0.04$ poise, which is fluid viscosity.

With the use of the calculated Womersley wave velocity given earlier, a value for the elastic modulus $\left(\mathrm{E}_{\mathrm{Y}}\right)$ is determined by substitution into the Moens-Korteweg equation ${ }^{8}$ :

$$
C_{o}=\sqrt{\frac{E_{\mathrm{Y}} h}{\rho 2 \mathrm{R}}}
$$

where $h=$ wall thickness. A paired two-tailed nonparametric test (Mann-Whitney U test) was used to determine statistical significance within groups. A $p$ value equal to or less than 0.05 was considered statistically significant.

\section{Results}

Hypoxia. Hypoxia significantly altered baseline pulmonary arterial hemodynamics in both groups of animals. Hypoxia caused large increases in pulmonary artery pressure in both age groups. Pulmonary artery flow and left atrial pressure were not altered in either group. The net result was a large increase in pulmonary vascular resistance in each group (Table I). The increase in input mean impedance in 48-hour-old and 14-day-old animals (81\% vs $92 \%$, $p=0.94)$ was similar. Characteristic impedance, modulus of elasticity, and the pulmonary artery radius at mean pulmonary artery pressure were unchanged in the 48-hour-old piglets. In contrast, characteristic impedance increased by $90 \%$, and modulus of elasticity increased by nearly $400 \%$ in the older animals (Fig. 1). This was accompanied by 

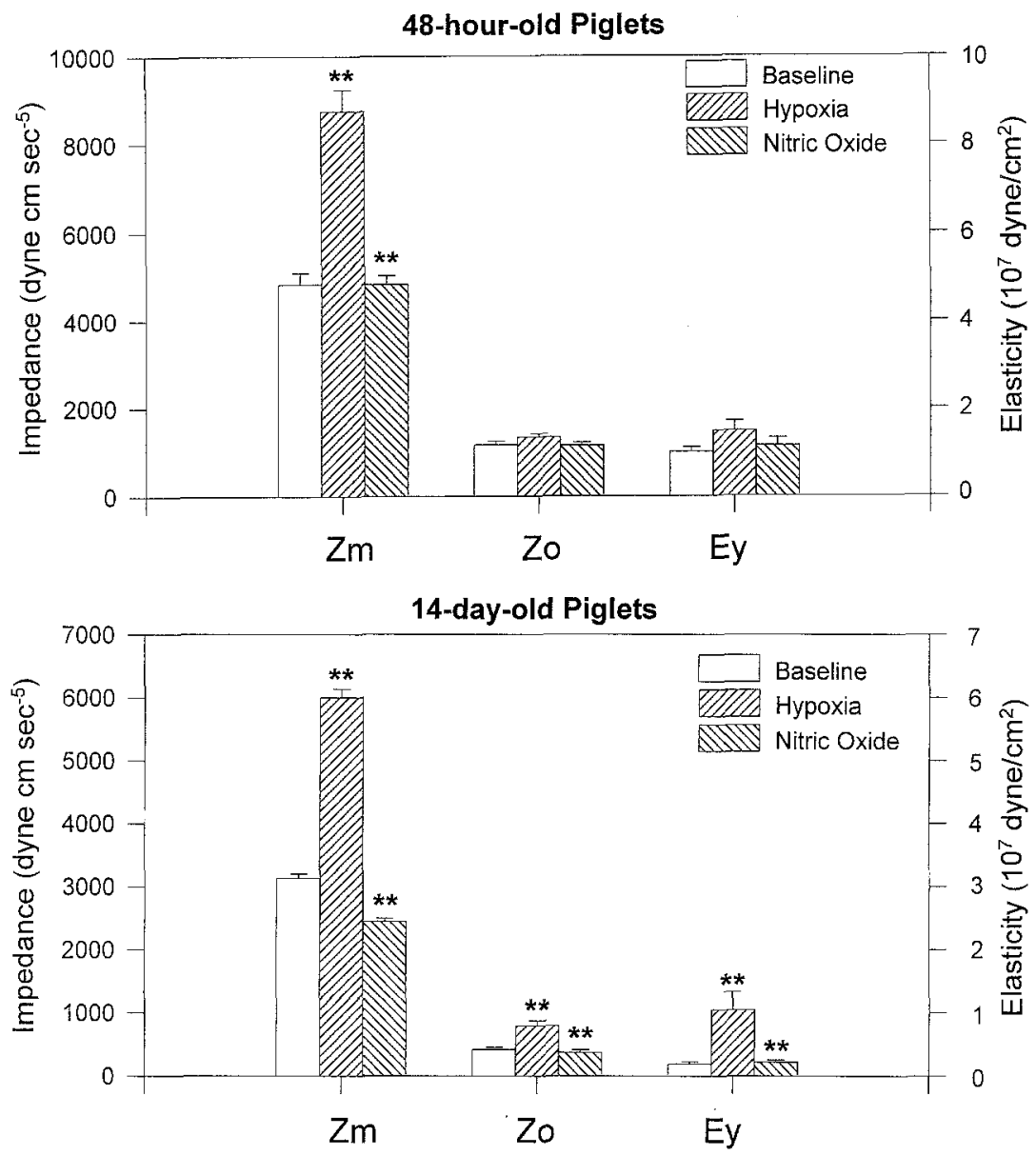

Fig. 1. Impedance and modulus of elasticity response to hypoxia and nitric oxide. Groups represent input mean impedance $(\mathrm{Zm})$, characteristic impedance $(\mathrm{Zo})$, and modulus of elasticity (Ey). Double asterisks indicate $p<0.01$ versus preceding intervention. Vertical error bars represent plus or minus standard error of the mean. Baseline data were obtained after L-NA administration.

a significant, but smaller ( $9 \%$ ) increase in the radius at mean pulmonary artery pressure in the older animals (Table I). Baseline values for $\mathrm{pH}(7.42 \pm$ $0.03,48$-hour-old animals) and (7.39 $\pm 0.03,14$-dayold animals $)$ and $\mathrm{PaCO}_{2}(35.9 \pm 1.8 \mathrm{~mm} \mathrm{Hg}, 48$ hour-old animals) and (37.2 $\pm 1.5 \mathrm{~mm} \mathrm{Hg}, 14$-dayold animals) were not altered. Aortic pressure was not changed, whereas oxygen saturation and $\mathrm{PaO}_{2}$ fell with hypoxia in both age groups (Table I).

Nitric oxide. Inhaled nitric oxide lowered pulmonary artery pressure and pulmonary vascular resistance in both age groups. Pulmonary artery flow was not altered by nitric oxide in the 48 -hour-old animals but increased in the older animals. Left atrial pressure was not altered in either group (Table I). Nitric oxide caused input mean impedance to fall to baseline levels in 48-hour-old animals and to fall significantly below baseline values $(2449 \pm 54$ vs $3129 \pm 73, p=0.016)$ in older animals. There was no alteration in characteristic impedance, modulus of elasticity, or the radius at mean pulmonary artery pressure in the 48-hour-old animals. In 14-day-old animals nitric oxide decreased characteristic impedance and modulus of elasticity to baseline levels. However, the radius at mean pulmonary artery pressure was not altered by nitric oxide inhalation. Hypoxia caused $\mathrm{PaO}_{2}$ and oxygen saturation to fall, whereas aortic pressure was unaltered (Table I). Neither pH $(7.40 \pm 0.03$, 48-hour-old animals; $7.38 \pm 0.03$, 14-day-old animals) nor $\mathrm{Paco}_{2}$ (38.1 \pm $2.3 \mathrm{~mm} \mathrm{Hg}$, 48-hour-old animals; $39.9 \pm 1.9 \mathrm{~mm} \mathrm{Hg}$, 14-day-old animals) was altered. 


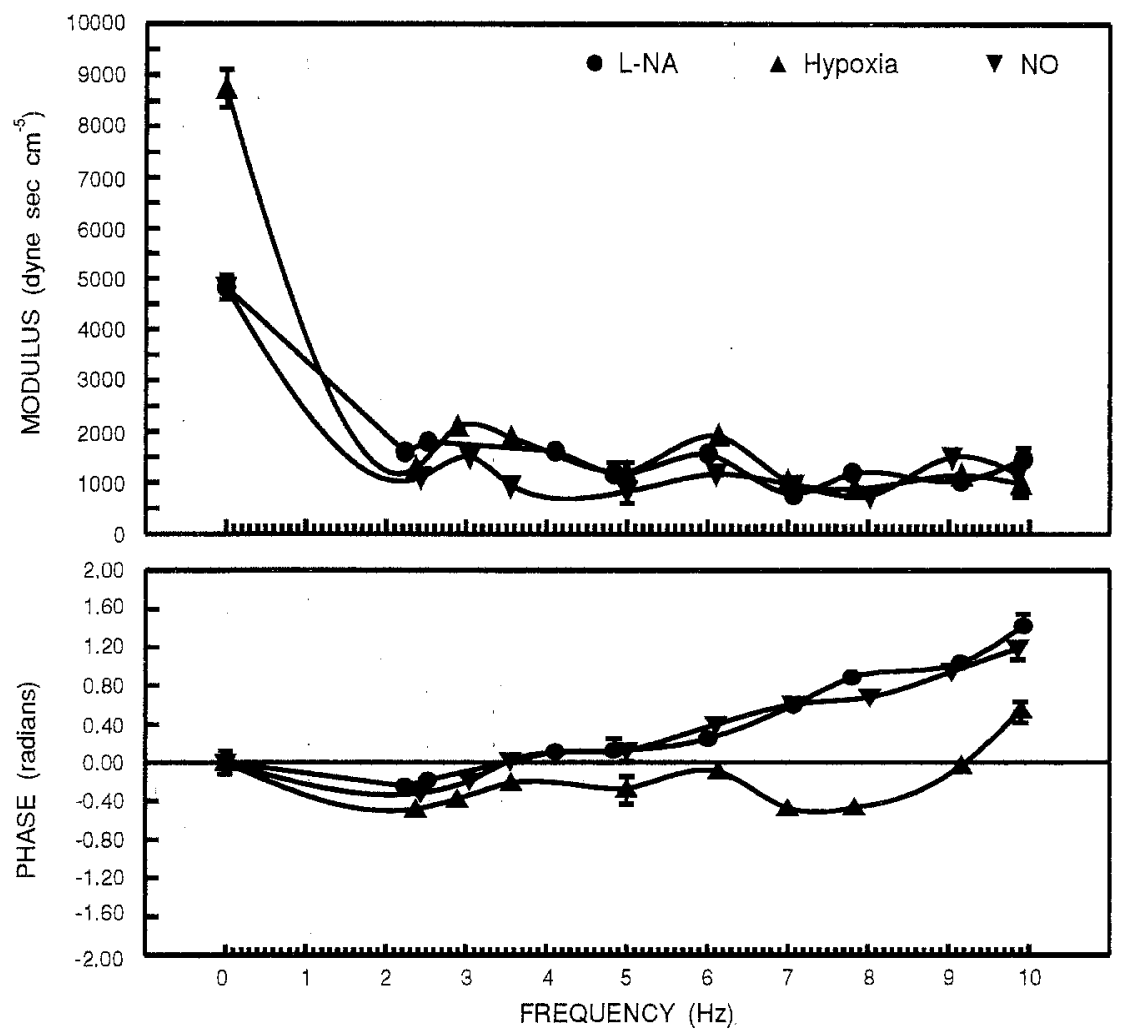

Fig. 2. Impedance moduli and corresponding phase angles for 48-hour-old piglets at baseline (after L-NA), during hypoxic inhalation, and during nitric oxide $(N O)$ inhalation. Mean moduli plus or minus standard error of the mean at selected frequencies are shown. Input mean impedance is at $0 \mathrm{~Hz}$ and characteristic impedance is between 3 and $10 \mathrm{~Hz}$.

\section{Discussion}

Current understanding of the importance of the vascular endothelium stems from the pioneering work of Furchgott and Zawadzki ${ }^{1}$ in 1980 . Their discovery that acetylcholine-induced vasodilatation required an intact endothelium was attributed to the presence of a labile humoral factor released from the endothelial cell. EDRF was subsequently identified as nitric oxide or a closely related compound. ${ }^{10}$ Its synthesis from the amino acid arginine and the ability to inhibit its production with analogs of L-arginine (i.e., L-NA) represent a powerful, easily exploited system for studying the role of endogenously produced nitric oxide in modulating resting hemodynamics and pharmacologic responses. ${ }^{11,12}$

Hypoxia and its potential for precipitating pulmonary hypertensive crises in neonates has long been appreciated by cardiac surgeons. ${ }^{13}$ Less clear is how the events associated with normal maturation affect this response. Several in vitro studies have indicated that the endothelium is not fully responsive at birth but rather matures to a fully functional state during the first few days after birth. Abman and associates ${ }^{14}$ showed that pulmonary artery rings from fetal sheep have less EDRF activity than do the rings of postnatal animals. ${ }^{14}$ Zellers and Vanhoutte ${ }^{15}$ demonstrated in piglet pulmonary artery rings an increase in endothelium-dependent contractions with increasing age in the early postnatal period. These investigators and others have also shown that the response to sodium nitroprusside (an endotheliumindependent vasodilator) is not affected by age, indicating early and complete function of the vascular smooth muscle. This is confirmed in our intact animal preparation as inhaled nitric oxide, an endothelium-independent vasodilator, decreased pulmonary vascular resistance and input mean impedance in both age groups despite inhibition of nitric oxide synthase. This response suggests the guanylate cyclase enzyme in the vascular smooth muscle is functional and capable of producing cyclic 

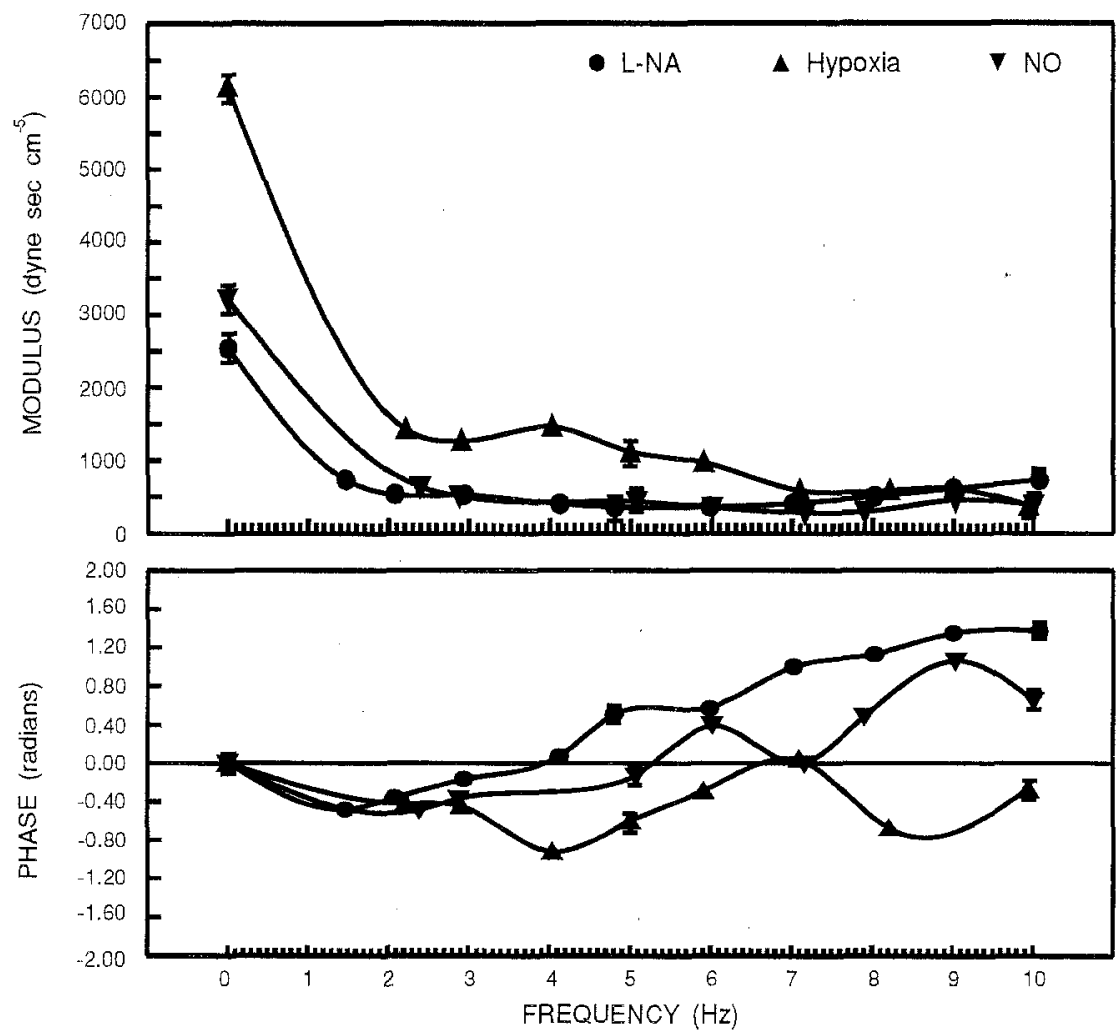

Fig. 3. Impedance moduli and corresponding phase angles for 14-day-old piglets at baseline (after L-NA), during hypoxic inhalation, and during nitric oxide (NO) inhalation. Mean moduli plus or minus standard error of the mean at selected frequencies are shown. Input mean impedance is at $0 \mathrm{~Hz}$ and characteristic impedance is between 3 and $10 \mathrm{~Hz}$.

guanosine monophosphate regardless of age. Therefore, maturational differences in the guanylate cyclase/cyclic guanosine monophosphate system are unlikely to be responsible for the age-related differences observed in the characteristic impedance response.

The study of pulmonary vascular impedance allows for a more complete analysis of the energy contained within the pulmonary arterial pressure and flow waveforms. Interpretation of these frequency-dependent measurements allows for a regional analysis of the vascular bed being studied. Input mean impedance occurs at $0 \mathrm{~Hz}$ and is therefore highly analogous to the nonpulsatile term pulmonary vascular resistance. Both groups underwent large increases in input mean impedance with hypoxia, indicating vasoconstriction at the level of the distal arterioles (Figs. 2 and 3). On exposure to inhaled nitric oxide, both groups experienced arteriolar vasodilation. Input mean impedance and pulmonary vascular resistance re- turned to prehypoxic levels, indicating an ability of the exogenously applied nitric oxide to functionally replace the endogenous nitric oxide. In 14-day-old animals the input mean impedance actually fell below prehypoxic levels (see Fig. 1). This may represent a tone-dependent difference in the response to inhaled nitric oxide, with older animals being more responsive. A second explanation is suggested by the work reported by Moncada and associates ${ }^{16}$ in rat aortic rings. In these experiments an acute and very rapid supersensitivity to exogenously administered nitric oxide occurred after inhibition of endothelium-derived nitric oxide. This phenomenon has been described during exposure to an exogenous mediator after removal of the endogenous form and is primarily a result of a specific supersensitivity at the level of the effector protein-soluble guanylate cyclase in our experiments. This would explain not only the large fall in input mean impedance in the 14-day-old animals, but also the 
observation by other investigators using intact animal preparations that inhaled nitric oxide does not vasodilate the nonhypoxic/nonhypercapnic pulmonary arterial circulation. ${ }^{17}$ The presence of a functional endothelium in these animals precludes the development of supersensitivity and may be reflected in the relative unresponsiveness to inhaled nitric oxide.

Characteristic impedance, that portion of the impedance modulus graph between 3 and $10 \mathrm{~Hz}$, is not influenced by reflected waves and therefore more accurately reflects changes in the geometry and compliance of the larger, more proximal pulmonary vessels. In our experiments, 14-day-old animals underwent a near doubling of characteristic impedance with hypoxia (Fig. 1), representing either a "stiffening" (increased modulus of elasticity) of the vessels or true vasoconstriction, in which the radius of the vessel is decreased. These older animals, in fact, underwent an increase in radius caused by the increased transmural distending pressure represented by the elevated pulmonary artery pressure. The younger animals, operating at a higher resting tone, with a less compliant vessel wall, do not undergo this passive distention. The increase in characteristic impedance seen in the older animals is therefore explained by the increase in the vessel wall stiffness (modulus of elasticity) that we measured. This represents a disadvantageous coupling between the right ventricle and the main pulmonary arteries. The importance of this effect can be seen when nitric oxide is applied and the fall in characteristic impedance and modulus of elasticity are accompanied by a significant improvement in pulmonary artery flow. These changes are not observed in the already elevated characteristic impedances of the neonatal animals and likely represent a maturational phenomenon related to the normal functional and structural changes that occur in this period of development.

These findings hold important implications in the management of very young patients requiring cardiac surgery. The presence of congenital cardiac defects and pulmonary hypertension have been shown to cause pulmonary artery endothelial cell abnormalities in human beings. ${ }^{18}$ In addition, both surgical manipulation and cardiopulmonary bypass further damage the endothelium. ${ }^{5}$ Differences in the response of neonatal and infant piglets with a dysfunctional endothelium in this study serve to emphasize the disparity in very young patients and in patients only hours or days older. Our studies indicate that older animals undergo an increase in stiffness of the proximal pulmonary arteries not seen in the neonatal animals. This additional deleterious effect of hypoxia in the older animals may explain the observation by Hanley and associates ${ }^{18}$ that infants with truncus arteriosus older than 30 days at the time of surgical repair are more likely to have postoperative courses complicated by pulmonary hypertension. Future studies may define the differences in pathways responsible for these unique responses and allow tailoring of treatment for patients of different physiologic ages.

\section{REFERENCES}

1. Furchgott RF, Zawadzki JV. The obligatory role of endothelial cells in the relaxation of arterial smooth muscle by acetylcholine. Nature 1980;288:373-6.

2. Greenwald SE, Johnson RJ, Haworth SJ. Pulmonary vascular input impedance in the newborn and infant pig. Cardiovasc Res 1984;18:44-50.

3. Fineman JR, Wong J, Morin FC III, Wild LM, Soifer SJ. Chronic nitric oxide inhibition in utero produces pulmonary hypertension in newborn lambs. J Clin Invest 1994;93:2675-83.

4. Wessel DL, Adatia I, Giglia TM, Thompson JE, Kulik TJ. Use of inhaled nitric oxide and acetylcholine in the evaluation of pulmonary hypertension and endothelial function after cardiopulmonary bypass. Circulation 1993;88(Pt 1): 2128-38.

5. Soyombo AA, Angelini GD, Newby AC. Neointima formation is promoted by surgical preparation and inhibited cyclic nucleotides in human saphenous vein organ cultures. J Thorac Cardiovasc Surg 1995;109:2-12.

6. Dyar O, Young JD, Howell S, Johns E. Dose-dependent relationship for inhaled nitric oxide in experimental pulmonary hypertension in sheep. Br J Anaesth 1993;71: $702-8$.

7. DeBono EF, Caro CG. Effect of lung inflating pressure on pulmonary blood pressure and flow. Am J Physiol 1963;205: 1178-86.

8. Hopkins RA, Hammon JW Jr, McHale PA, Smith PK, Anderson RW. An analysis of the pulsatile hemodynamic responses of the pulmonary circulation to acute and chronic pulmonary venous hypertension in the awake dog. Circ Res 1980;47:902-10.

9. Womersley JR. Oscillatory flow in arteries: the constrained clastic tube as a model of arterial flow and pulse transmission. Physiol Med Biol 1957;2:178-87.

10. Palmer RMJ, Ferridge AG, Moncada S. Nitric oxide release accounts for the biological activity of endothelium-derived relaxing factor. Nature 1987;327:524-6.

11. Palmer RMJ, Rees DD, Ashton DS, Moncada S. L-Arginine is the physiological precursor for the formation of nitric oxide in endothelium-dependent relaxation. Biochem Biophys Res Commun 1988;153;1251-6.

12. Nelin LD, Dawson CA. The effect of $N \omega$-nitro-L-arginine methylester on hypoxic vasoconstriction in the neonatal pig lung. Pediatr Res 1993;34:349-53.

13. Hopkins RA, Bull C, Haworth SG, de Leval MR, Stark J. 
Pulmonary hypertensive crisis following surgery for congenital heart defects in young children. Eur J Cardiovasc Thorac Surg 1991;5:628-31.

14. Abman SH, Chatfield BA, Rodman DM, Hall SL, McMurtry IF. Maturational changes in endothelium-derived relaxing factor activity of ovine pulmonary arteries in vitro. Am $\mathbf{J}$ Physiol 1991;260:L280-5.

15. Zellers TM, Vanhoutte PM. Endothelium-dependent relaxations of piglet pulmonary arteries augment with maturation. Pediatr Res 1991;30:176-80.
16. Moncada S, Rees DD, Schulz R, Palmer RMJ. Developmen and mechanism of a supersensitivity to nitrovasodilators after inhibition of vascular nitric oxide synthesis in vivo. Proc Natl Acad Sci U S A 1990;88:2166-70.

17. Van Camp JR, Yian C, Lupinetti FM. Regulation of pulmonary vascular resistance by endogenous and exogenous nitric oxide. Ann Thorac Surg 1994;58:1025-30.

18. Hanley FL, Heinemann MK, Jonas RA, Mayer JE, Cook NR, Wessel DL, et al. Repair of truncus arteriosus in the neonate. J Thorac Cardiovasc Surg 1993;105;1047-56.

\section{Availability of Journal back issues}

As a service to our subscribers, copies of back issues of The Journal of Thoracic and Cardiovascular Surgery for the preceding 5 years are maintained and are available for purchase from Mosby at a cost of $\$ 15.00$ per issue until inventory is depleted. The following quantity discounts are available: $25 \%$ off on quantities of 12 to 23 , and one third off on quantities of 24 or more. Please write to Mosby-Year Book, Inc., Subscription Services, 11830 Westline Industrial Drive, St. Louis MO 63146-3318, or call 800-453-4351 or 314-453-4351 for information on availability of particular issues. If unavailable from the publisher, photocopies of complete issues may be purchased from UMI, 300 N. Zeeb Rd., Ann Arbor, MI 48106, 313-761-4700. 